\title{
The Use of Granular Cyclopentanone as Alternative to Artificial Source of Carbon Dioxide in Improved Passive Outdoor Host Seeking Device (POHD)
}

\author{
Stella T. Kessy, ${ }^{1}$ Bruno A. Nyundo, ${ }^{2}$ Ladslaus L. Mnyone, ${ }^{1,3,4}$ and Issa N. Lyimo ${ }^{1}{ }^{1}$ \\ ${ }^{1}$ Department of Environmental Health and Ecological Sciences, Ifakara Health Institute, P.O. Box 53, Off Mlabani Passage, \\ Ifakara, Morogoro, Tanzania \\ ${ }^{2}$ Zoology and Wildlife Conservation Department, College of Natural and Applied Science, University of Dar Es Salaam, \\ P.O. Box 35091, Dar Es Salaam, Tanzania \\ ${ }^{3}$ Pest Management Centre, Sokoine University of Agriculture, P.O. Box 3110, Morogoro, Tanzania \\ ${ }^{4}$ School of Public Health, Faculty of Health Sciences, University of the Witwatersrand, Johannesburg, South Africa
}

Correspondence should be addressed to Issa N. Lyimo; ilyimo@ihi.or.tz

Received 19 October 2019; Revised 7 April 2020; Accepted 16 May 2020; Published 13 June 2020

Academic Editor: Gabriella Cancrini

Copyright $\odot 2020$ Stella T. Kessy et al. This is an open access article distributed under the Creative Commons Attribution License, which permits unrestricted use, distribution, and reproduction in any medium, provided the original work is properly cited.

Reliable sources of $\mathrm{CO}_{2}$ that are relatively cheap, obtainable, and easy to sustain are immediately required for scaling up of odorbaited mosquito surveillance and control devices. Several odor-baited devices are in the pipeline; however, their scale-up against residual malaria transmission, particularly in resource poor areas, is limited by the unavailability of reliable sources of $\mathrm{CO}_{2}$ and reliance on electrical power sources among other factors. We evaluated the use of granular cyclopentanone as an alternative to artificial or yeast fermentation-produced $\mathrm{CO}_{2}$ in passive outdoor host seeking device (POHD). Experiments were conducted against semifield reared An. arabiensis within the semifield system (SFS) at Ifakara Health Institute. Mosquitoes were tested against odor-baited POHDs augmented with yeast fermentation-produced $\mathrm{CO}_{2}$, granular cyclopentanone, attractive blends (Mbita or Ifakara), or their combinations. An insecticide, bendiocarb, was a killing agent used as a proxy for marking the mosquitoes visit the POHDs. Relative attractiveness of different treatment combinations was compared based on the proportion of dead mosquitoes that visited the POHD. The POHD augmented with granules of cyclopentanone alone was attractive to An. arabiensis as much as, or more than, POHDs augmented with yeast fermentation-produced $\mathrm{CO}_{2}$. The POHD baited with $\mathrm{CO}_{2}$ attracted more mosquitoes than those POHDs baited with synthetic blends alone; when these blends are combined with $\mathrm{CO}_{2}$, they attracted more mosquitoes than individual blends. More importantly, such POHDs baited with cyclopentanone attracted far greater proportion of mosquitoes than the POHD baited with either Mbita or Ifakara blend alone. The granular cyclopentanone strongly enhanced/potentiated the attractiveness of POHD baited with Mbita blends against mosquitoes compared to that of POHD baited with Ifakara blend. Moreover, the granular cyclopentanone retained its residual activity against An. arabiensis for up to 2 months after application particularly when used in combination with Mbita blend. In conclusion, this study demonstrates that cyclopentanone granules have the potential to substitute sources of $\mathrm{CO}_{2}$ in outdoor-based surveillance and control devices, thus warranting evaluation of such alternative under realistic field conditions.

\section{Introduction}

Mosquitoes play an overwhelming role in transmitting several vector-borne diseases to humans such as malaria, lymphatic filariasis, yellow fever, rift valley, dengue fever, Zika, and chikungunya [1-7]. Of these diseases, malaria causes the greatest health and socioeconomic burden $[4,6,8]$, with 228 million cases and 405,000 deaths which are highly concentrated in sub-Saharan Africa $[4,6]$.

Mosquito vectors detect and locate their preferential blood meal sources mainly through chemoreception of volatile cues liberated from their hosts [9-14]. Mosquito 
antennae and maxillary palps have several receptors $[10,12,15-18]$, which enable them to efficiently detect both the skin odors and carbon dioxide $\left(\mathrm{CO}_{2}\right)$ plume from humans $[13,17,19-24]$. The $\mathrm{CO}_{2}$ is one of the most important long range attractants (normally detected at a range of $18-60 \mathrm{~m})[21,25,26]$; it attracts both the opportunistic (e.g., An. arabiensis) and anthropophilic mosquitoes (e.g., Anopheles gambiae s.s., and Culex quinquefasciatus) $[19,27-29]$. The combination of $\mathrm{CO}_{2}$ and skin odors has been shown to significantly attract high proportion of mosquitoes compared to $\mathrm{CO}_{2}$ or skin odor alone $[11,13,14,17,20,22,30-32]$. Therefore, $\mathrm{CO}_{2}$ is now widely used to enhance/potentiate the efficacy of odor-baited control and sampling devices [13, 30, 31, 33-40].

The existing odor-baited traps/devices rely on conventional sources of $\mathrm{CO}_{2}$ for sampling mosquitoes [41-43]. These conventional sources of $\mathrm{CO} 2$ include pressurized gas cylinders of industrial $\mathrm{CO}_{2}[30,40]$, dry ice $[33,39,44]$, and burning of propane [45]. Examples of traps baited with $\mathrm{CO}_{2}$ include BG-sentinel traps [40, 46], CDC light traps [39, 40], counterflow geometry traps [47], Mosquito Magnet-X traps (MMX-trap) [38], mosquito landing boxes [35], and mosquito trapping boxes [33]. However, these conventional sources of $\mathrm{CO}_{2}$ are expensive, unobtainable, and labor intensive to transport and sustain for large scale surveillance and control programs in resource poor areas [48]. Therefore, reliable sources of $\mathrm{CO}_{2}$ that are relatively less expensive, easy to use, and easy to sustain in remote poor resource settings are urgently required for use in odor-baited devices. Otherwise, the control of residual malaria transmission, which occurs almost exclusively outdoors, will remain a difficult endeavor.

Recently, several organic sources of $\mathrm{CO}_{2}$ have been proposed for use in mosquito traps for surveillance $[32,49,50-52]$. These organic sources of $\mathrm{CO}_{2}$ include yeast fermentation of sugar/sucrose and molasses [32, 52-54], electrolyzed oxalic acids (Harwood et al., 2014), granular $\mathrm{CO}_{2}$ sachets [55], and food-grade sources such as mixture of citric acid, water, and powdered sodium bicarbonate (NaHCO3), or vinegar (5\%) mixed with sodium bicarbonate (NaHCO3) [56]. However, traps baited with $\mathrm{CO}_{2}$ from organic sources attract relatively fewer mosquitoes than those baited with industrial $\mathrm{CO}_{2}$ in pressurized gas cylinders or dry ice $[55,56]$. These organic sources of $\mathrm{CO}_{2}$ are still expensive and logistically difficult to use for large scale surveillance and control programs because they require frequent replenishment of materials to extent residual activity. Therefore, the portable, easy to use, long-lasting, and cheaper novel sources of $\mathrm{CO}_{2}$ that may attract high proportions of mosquitoes, comparable to or higher than those attracted with traditional sources of $\mathrm{CO}_{2}$, are urgently required for large scale application of odor-baited devices in poor resource countries.

One of the desirable options could be the use of novel compounds that mimic $\mathrm{CO}_{2}$ such as cyclopentanone $\left(\mathrm{C}_{5} \mathrm{H}_{8} \mathrm{O}\right)$ [57, 58], acetone [59], and 2-butanone [60, 61]. These compounds activate $\mathrm{CO}_{2}$ receptor (cpA) neuron on the maxillary palps of mosquitoes, and some of them have been tested against Anopheles, Culex, and Aedes mosquitoes as substitutes for $\mathrm{CO}_{2}$ in odor-baited traps without success $[17,58,60]$. Traps baited with liquid formulation of cyclopentanone had similar catches of Culex quinquefasciatus to those traps baited with industrial $\mathrm{CO}_{2}$ under semifield conditions [17], but not in the field [58]. Similarly, the liquid formulation of 2-butanone increased attractiveness of synthetic blend (e.g., Mbita blend) to mosquitoes including Anopheles gambiae and Anopheles funestus the same as $\mathrm{CO}_{2}$ in the odor-baited traps under the field but not semifield environments [60]. However, it was hypothesized that liquid formulation of cyclopentanone or 2-butanone in a cotton wick may depreciate relatively quickly due to variations of wind speed, moisture, temperature, and competing odors from the surrounding natural vegetation $[58,60]$. Therefore, there is a need for slow release formulations of cyclopentanone or other $\mathrm{CO}_{2}$ mimics such as 2butanone to enhance further development and large scale use of traps and odor-baited outdoor control devices $[17,58,60]$. This study aimed to (i) evaluate the potential of cyclopentanone granules to enhance/potentiate the attractiveness of synthetic blends in POHD against An. arabiensis, (ii) compare the efficacy of POHD baited with granular and strip formulation of cyclopentanone against An. arabiensis, and (iii) assess the residual activity/persistence of such formulations against An. arabiensis.

\section{Materials and Methods}

2.1. Study Site. Experiments were conducted within the semifield system (SFS) located at Kining'ina village in Kilombero Valley (Figure 1), about $6 \mathrm{~km}$ from Ifakara town. The SFS has several chambers $(2.97 \times 6.70 \times 2.80 \mathrm{~m})$ with temperature range from 26 to $32^{\circ} \mathrm{C}$.

2.2. Mosquitoes. The colony of An. arabiensis was established in 2008 by collection of gravid females from the wild population at Sagamaganga village, Kilombero Valley (8.0667 S, 36.8000 E) [62]. This colony of mosquitoes is reared under ambient conditions in one chamber $(3.30 \times 2.70 \times 2.50 \mathrm{~m})$ of the semifield system $(60 \times 20 \mathrm{~m})$ [62]. The temperature and relative humidity in this system range from 25 to $32^{\circ} \mathrm{C}$ and from 70 to $90 \%$, respectively. The larvae are kept in rearing basins and are fed on TetraMin ${ }^{\circledR}$ (Tetra $\mathrm{GmbH}$, Germany), as finely ground baby fish food flakes twice to three times a day. The adult mosquitoes are maintained inside the cages $(0.45 \times 0.45 \times 0.45 \mathrm{~m})$ with $10 \%$ glucose solution. Female An. arabiensis mosquitoes used throughout this study were 3-7 days old.

2.3. Improved POHD and Different Treatments. The improved POHD with bottom mosquito entrance was used in these experiments (Figure 2, Kessy et al., unpublished). Cyclopentanone, $\mathrm{CO}_{2}$, and synthetic blend (Mbita or Ifakara) $[36,63]$ were deployed as attractants in the improved POHD, singly or in combination to compare their attractiveness against $A n$. arabiensis female mosquitoes. The Mbita and Ifakara blends were designed and developed to either sachet containing granules or soaked nylon strips by 


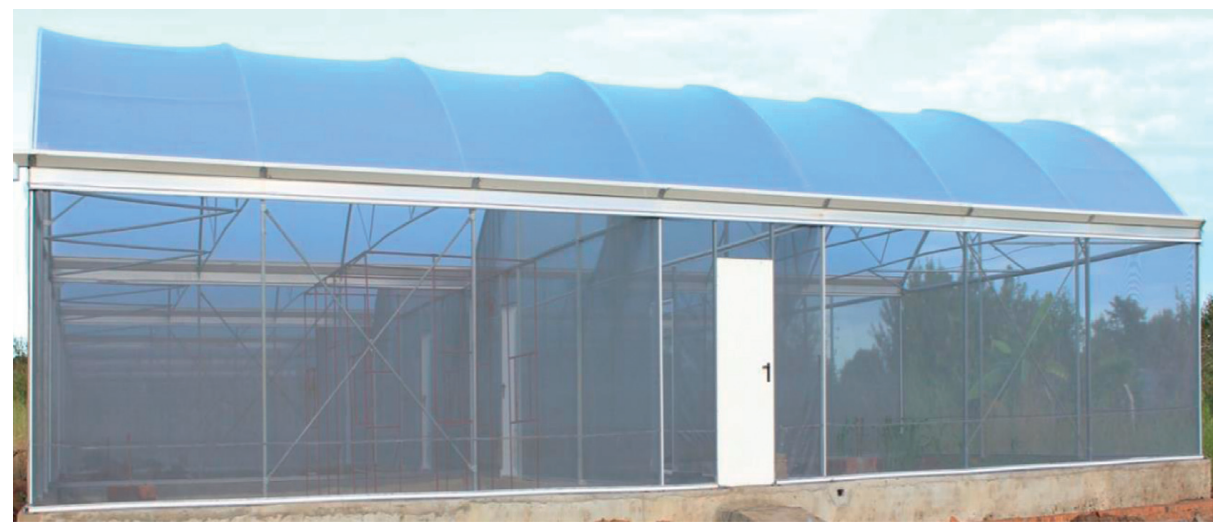

FIgure 1: A picture of the semifield system (SFS). This SFS is located at Ifakara Health Institute in Kining'ina village, Kilombero Valley, Southeastern Tanzania.
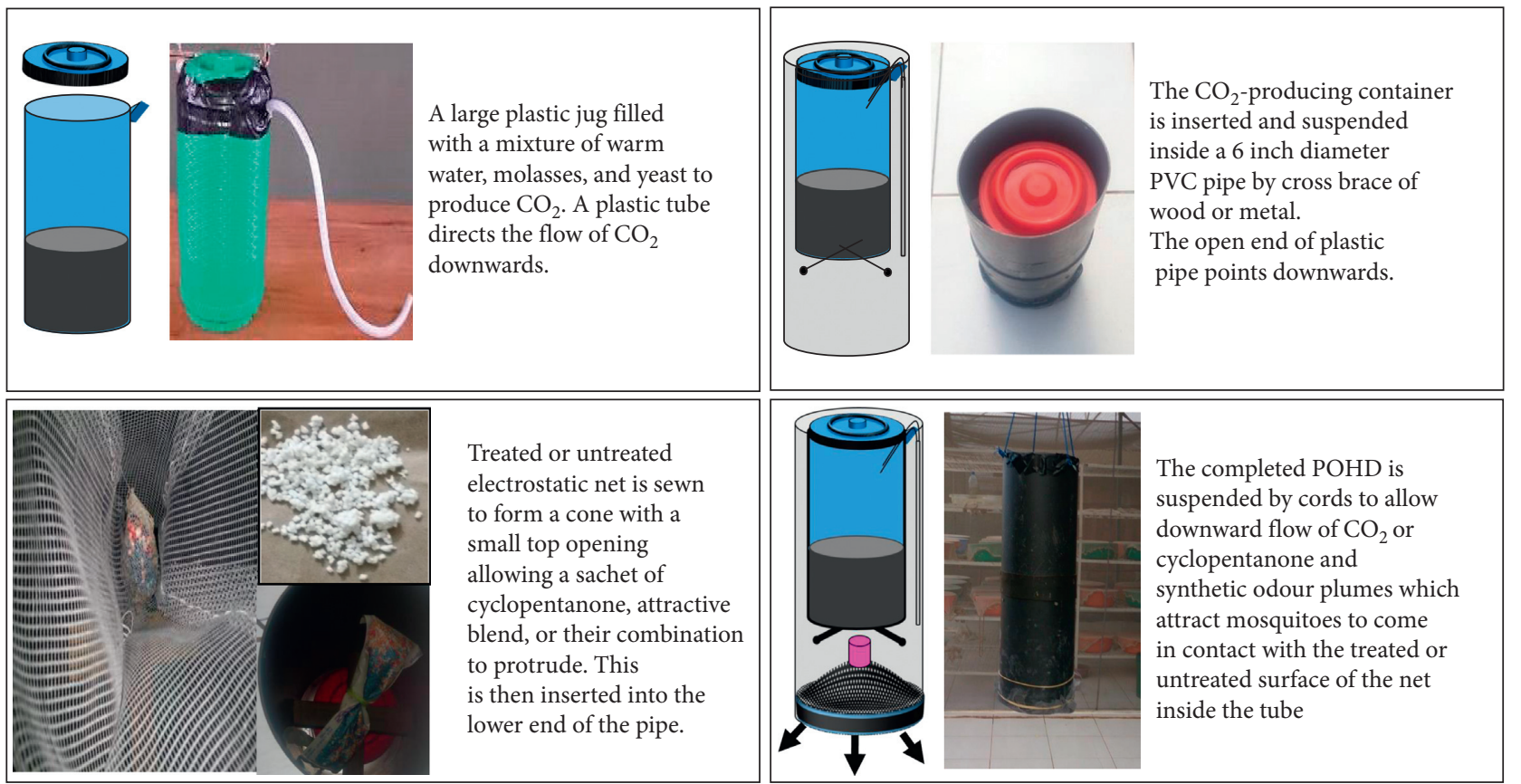

Treated or untreated electrostatic net is sewn to form a cone with a small top opening allowing a sachet of cyclopentanone, attractive blend, or their combination to protrude. This is then inserted into the lower end of the pipe.

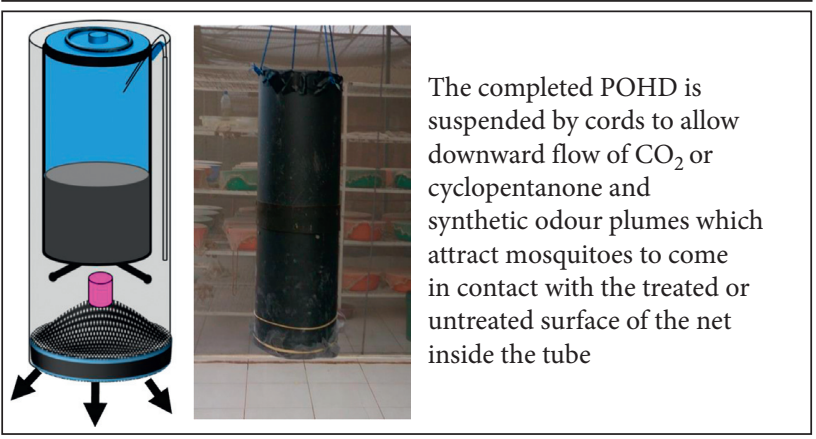

FIgURE 2: Schematic drawing and pictures showing improved passive host seeking device (POHD) with bottom placement of synthetic attractive blends and mosquito killing agent (bendiocarb). Components of the POHD are (a) the inner red jug containing mixture of warm water, molasses, and yeast for production of carbon dioxide $\left(\mathrm{CO}_{2}\right)$ and a rubber tube for channelling $\mathrm{CO}_{2}$ downwind; (b) the $\mathrm{CO} 2$-producing plastic jug is inserted and suspended inside 6-inch PVC pipe using fixed wood pieces; (c) a holed conical electrostatic netting untreated or treated with powdered bendiocarb and plugged with a bag/sachet containing granules of synthetic attractive blend, the granules of novel $\mathrm{CO}_{2}$ mimic compound, and $20 \%$ cyclopentanone as alternative to yeast fermentation-produced $\mathrm{CO}_{2}$; (d) a complete POHD with polyvinyl chloride (PVC) outer cover to allow downwind flow of odor and $\mathrm{CO}_{2}$ plumes to attract mosquitoes towards treated or untreated netting inside the device.

Biogents AG, Germany. Two forms of $\mathrm{CO}_{2}$ were used: (i) the yeast fermentation-produced $\mathrm{CO}_{2}$ from modified mixture of yeast $(8.75 \mathrm{~g}$ ) and molasses (250 g) [50], and a total volume of $1 \mathrm{~L}$ of warm water based on previous studies that produced $\mathrm{CO}_{2}$ using at least $1 \mathrm{~g}$ of yeast in a total volume of $\leq 1$ or $>1 \mathrm{~L}$ of water $[32,52,64,65]$, (ii) $20 \%$ cyclopentanone $\left(\mathrm{C}_{4} \mathrm{H}_{8} \mathrm{O}\right)$ used in previous studies [17], which was modified and formulated to granules and impregnated nylon strips by Biogents AG, Germany. The synthetic attractive blends and cyclopentanone were stored in the refrigerator at $4^{\circ} \mathrm{C}$ between experiments. A powder formulation of bendiocarb (Ficam D) was applied on electrostatic charged netting [66] to kill mosquitoes visiting the improved POHD. Bendiocarb is a nonrepellent insecticide that acts by contact against mosquitoes including the population of $A n$. arabiensis in Kilombero Valley [72]. These vector species are fully susceptible to bendiocarb (Lwetoijera et al., 2014; [72]; Matiya et al., 2019). Thus, bendiocarb was a suitable carbamate for use in POHD baited with lures to attract and kill any visiting mosquitoes 
and to quantify the number of dead mosquitoes as a proxy for attractiveness of the POHD to mosquitoes.

\section{Experimental Procedures}

3.1. Potentiating/Enhancing Effects of Cyclopentanone. The sachets of granular formulation or impregnated nylon strips of either Mbita $(\mathrm{Mb})$ or Ifakara blend (Ib) were hung inside the improved POHD. Eight (8) different treatment combinations were evaluated: (1) $\mathrm{CO}_{2}+$ cyclopentanone + odor blend + untreated netting (untreated), (2) bendiocarbtreated netting alone $(\mathrm{Be}),(3)$ odor blends $+\mathrm{Be}(\mathrm{Mb}$ or $\mathrm{Ib})$, (4) $\mathrm{CO}_{2}+\mathrm{Be}(\mathrm{CO})$, (5) cyclopentanone + $\mathrm{Be}$ (Cy), (6) $\mathrm{CO}_{2}+$ odor blends $+\mathrm{Be}(\mathrm{MbCO}$ or $\mathrm{IbCO})$, (7) cyclopentanone (Cy) + odor blends + Be (CyMb, or CyIb), and (8) odor blend $+\mathrm{CO}_{2}+\mathrm{Cy}+\mathrm{Be}(\mathrm{CyMbCO}$ or CyIbCO). The improved POHD components were assembled and hung at the middle of the chamber within the SFS, $0.25 \mathrm{~m}$ off the ground (Figures 2 and 3(a)). In each experiment, a total of 100 starved female mosquitoes ( 25 individuals per cup) were released at four different corners of the SFS against the aforesaid treatment combinations. Mosquitoes were left to forage for overnight. The next morning, all live or dead mosquitoes from inside the POHD and other parts of the SFS chamber were independently recovered, counted, and recorded. All live mosquitoes were kept in the semifield insectary, provided with $10 \%$ glucose solution, and monitored for mortality after $24 \mathrm{hrs}$. Treatment combinations were randomly alternated between the days of the experiments. Between experiments, any mosquitoes remaining inside the experimental SFS chamber were removed using CDC backpack aspirator to avoid spillover effect. These experiments were replicated three times for each treatment combination.

3.2. Persistence of Granular Cyclopentanone. Persistence of cyclopentanone was evaluated using a rectangular bioassay box $(1.87 \times 2.12 \times 1.15 \mathrm{~m})$, inside three different SFS chambers $(2.50 \times 9.50 \times 9.00 \mathrm{~m})$, one box per chamber (Figure $3(\mathrm{~b})$ ). The synthetic blend that was strongly enhanced by granular cyclopentanone from the efficacy experiment above, Mbita blend in this case, was selected to be combined with cyclopentanone in these experiments. Persistence was counted from the day the cyclopentanone started being used after preparation, and month is abbreviated as "mo" in the text and the figures. The treatment combinations were as follows: (1) fresh granules of cyclopentanone $(\mathrm{Cy})+$ Mbita blend $(\mathrm{Mb})+$ untreated netting (untreated), (2) fresh granules of Mbita blend alone (Mb), (3) 2 mo old granules of cyclopentanone + bendiocarbtreated netting-Be (2moCy), (4) 2 mo old granules of cyclopentanone $+\mathrm{Mb}+\mathrm{Be}(2 \mathrm{moCyMb})$, (4) fresh granules of cyclopentanone $+\mathrm{Be}$ (FreshCy), and (5) fresh granules of cyclopentanone $+\mathrm{Mb}+\mathrm{Be}$ (FreshCyMb). Then, improved POHD was assembled and hung at the middle of the rectangular box at $0.25 \mathrm{~m}$ off the ground (Figure $3(\mathrm{~b})$ ). The two sides of the box were closed with cardboard, but two holes $(0.11 \mathrm{~cm}$ in diameter) were made for the release of mosquitoes inside during experiments. Each time of the experiment, a total of 100 female mosquitoes starved for 6 hours without glucose were released inside the box through 4 holes (25 individual mosquitoes/holes $\times 4$ holes $=100$ mosquitoes) in the evening at 7:00 pm. Recapture and monitoring of mosquitoes were done following the same procedures as in the efficacy experiments above. These experiments were replicated three times for each treatment combination.

3.3. Comparing Efficacy of Different Formulations of Cyclopentanone. These experiments were conducted using rectangular bioassay boxes (in experiment 2 above), with the aim of comparing the efficacy of cyclopentanone applied on granules and nylon strips delivery formats against mosquitoes. The formulations of cyclopentanone were tested in combination with long-lasting granular formulation of Mbita blend (depicted from persistence experiments). Different treatment combinations evaluated in the improved POHD were as follows: (1) fresh cyclopentanone + Mbita blend + untreated netting, (2) fresh cyclopentanone strip $+\mathrm{Mb}+\mathrm{Be}$ (strips), and (3) fresh cyclopentanone granules $+\mathrm{Mb}+\mathrm{Be}$ (granules). The improved POHDs incorporated with different treatment combinations were assembled (independently) and hung at the center of the box (Figure 3(b)). Mosquitoes were exposed to improved POHDs, recaptured, and monitored for 24-hour mortality, in the same way described in experiments 1 and 2 above. These experiments were replicated three times for each treatment combination.

3.4. Ethical Considerations. The research team and technical assistants responsible for rearing and handling mosquitoes were routinely (i.e., after every 7 days) screened for malaria to ensure that experimental materials are free of malaria parasites. The semifield had double doors, and it was routinely checked to ensure that the screens were always intact to prevent escape of mosquitoes to the environment. The remains of bendiocarb and/or treated materials were disposed accordingly and thereafter incinerated. The ethical review and approval were granted by the Institutional Ethics Review Board (IRB) of Ifakara Health Institute (Ref: IHI/ IRB/No: 14-2013) and the Medical Research Coordinating Committee at the National Institute of Medical Research in Tanzania (NIMR/HQ/R.8a/Vol. IX/1784). This work was also granted permission for publication by National Institute of Medical Research in Tanzania (NIMR/HQ/P.12/Vol. XXVIII/93).

3.5. Statistical Analysis. Statistical analyses were conducted to test the efficacy of cyclopentanone as alternative to $\mathrm{CO}_{2}$ for enhancing/potentiating the attractiveness of synthetic blends, to determine the duration of their effects (persistence), and to compare between nylon strips and granular formulations against Anopheles arabiensis. Response variable measured in these experiments was proportion of mosquitoes killed by different treatments of 


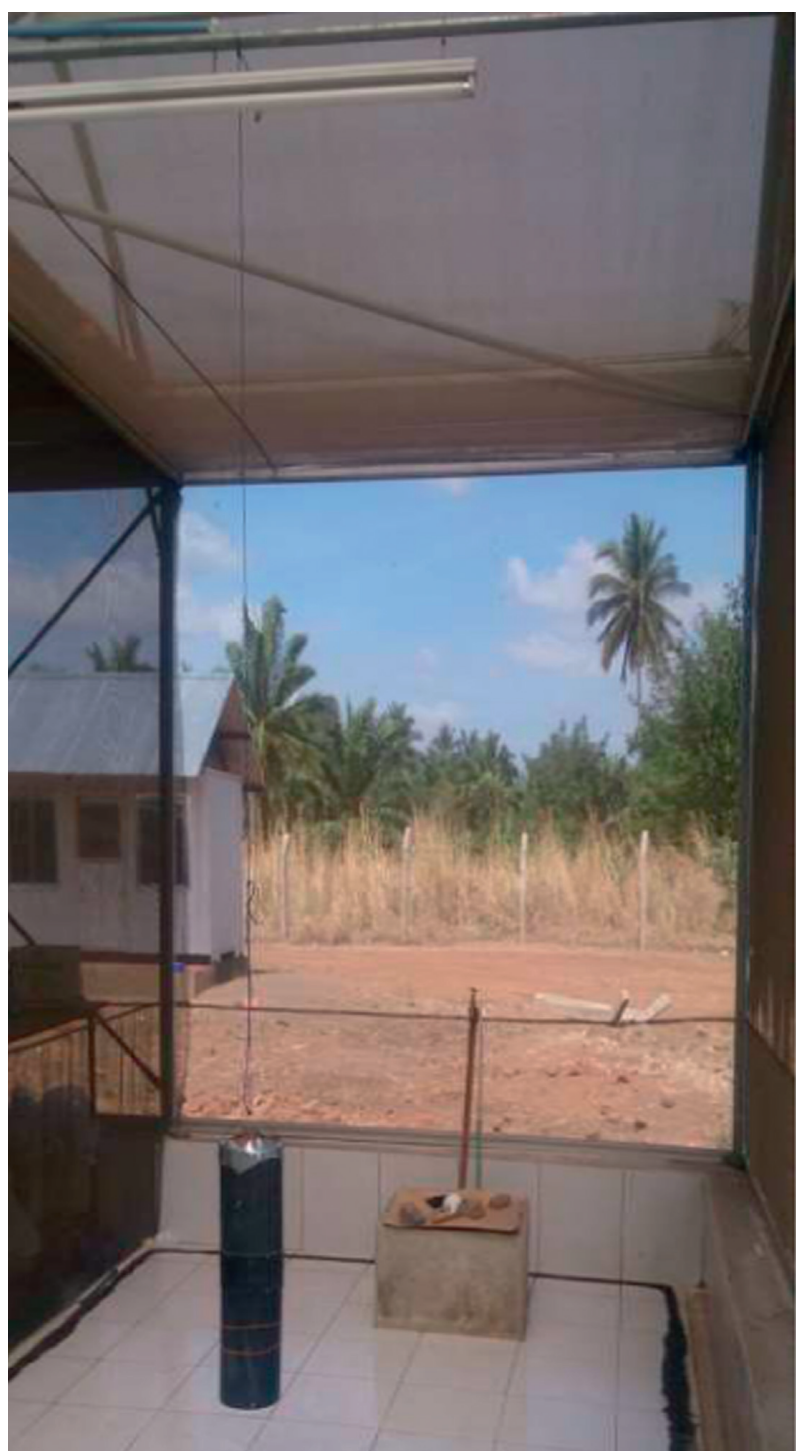

(a)

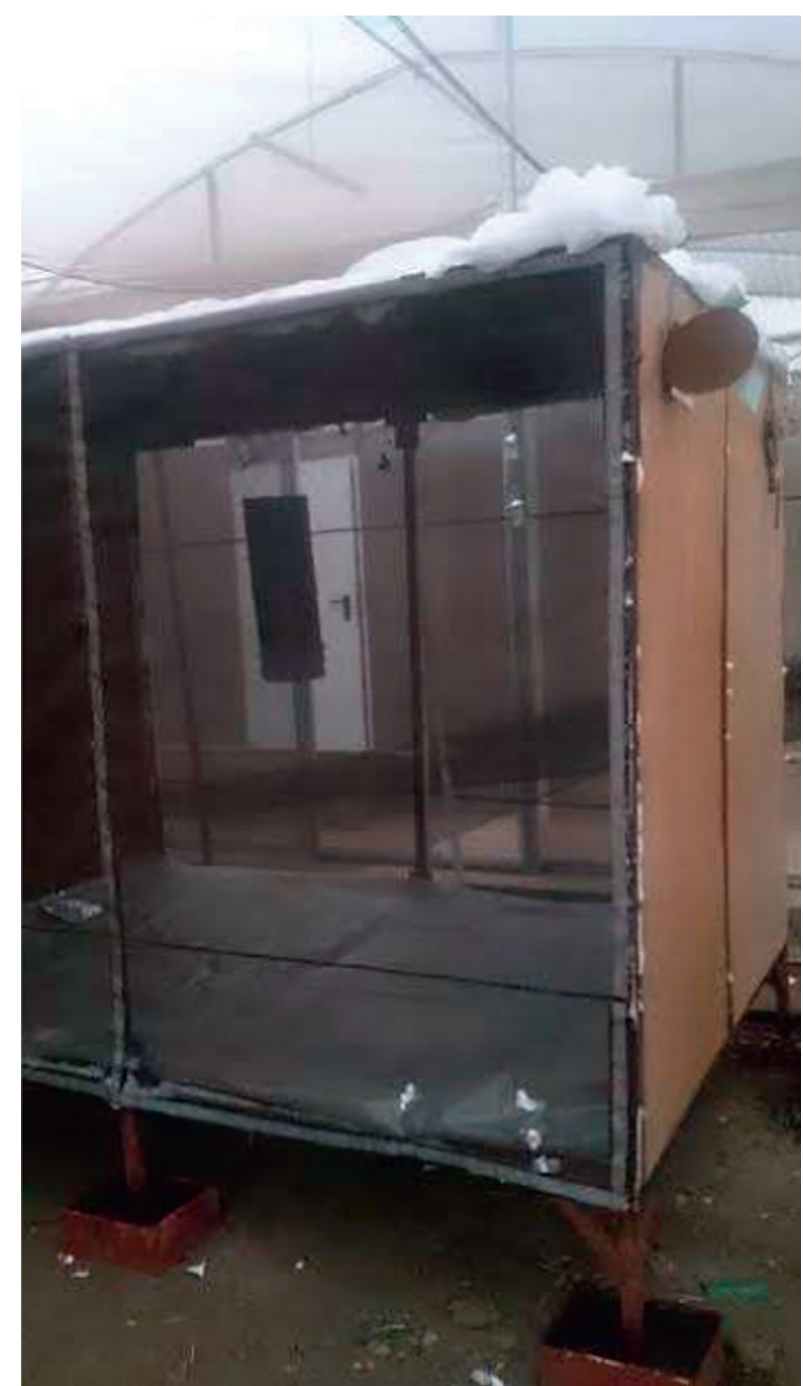

(b)

Figure 3: Improved passive host seeking device (POHD) was assembled and baited with attractants, combined with or without the mosquito killing agent (bendiocarb). This device was exposed to An. arabiensis by hanging in the middle of (a) chamber of the SFS and (b) rectangular bioassay box.

POHD. The response variable of proportion of dead mosquitoes was analyzed using generalized linear mixed effect models with binomial errors (glmer) in the R statistical software package [71]. The explanatory variables, "treatments," "blend type," and "formulations," were considered as the main effects, whereas "days" of the experiments were considered as random effects. A base model including only random effect of "day" was constructed. A sequential addition of the "main effects" and their interaction (treatment $\times$ blends or treatment formulation) to the base model was conducted to construct a maximal model (forward stepwise approach). A statistical significance of fixed effects and interaction term was generated and evaluated using likelihood ratio tests (LRTs). When the interaction terms were statistically significant, the main effect of either "blend type" or "formulation type" for each synthetic attractant was analyzed separately to generate estimates for the main effects. Then, the full model was used to perform a two-ways multiple comparisons using Tukey post hoc tests (adjusting for multiple comparison) to establish statistical significant differences between treatments.

\section{Results}

4.1. Potentiating/Enhancing Effect of Cyclopentanone. The attractiveness of improved POHD against Anopheles arabiensis was influenced by interaction between treatments and attractive blend types (treatment $*$ blend type: $\chi_{2}^{2}=2.56$, $P<0.001$, Figures 4(a) and 4(b), Tables 1 and 2). Overall, all treatments combinations of POHD baited with Mbita blend $\mathrm{Mb}$ ) including augmentation with cyclopentanone (Cy) and 


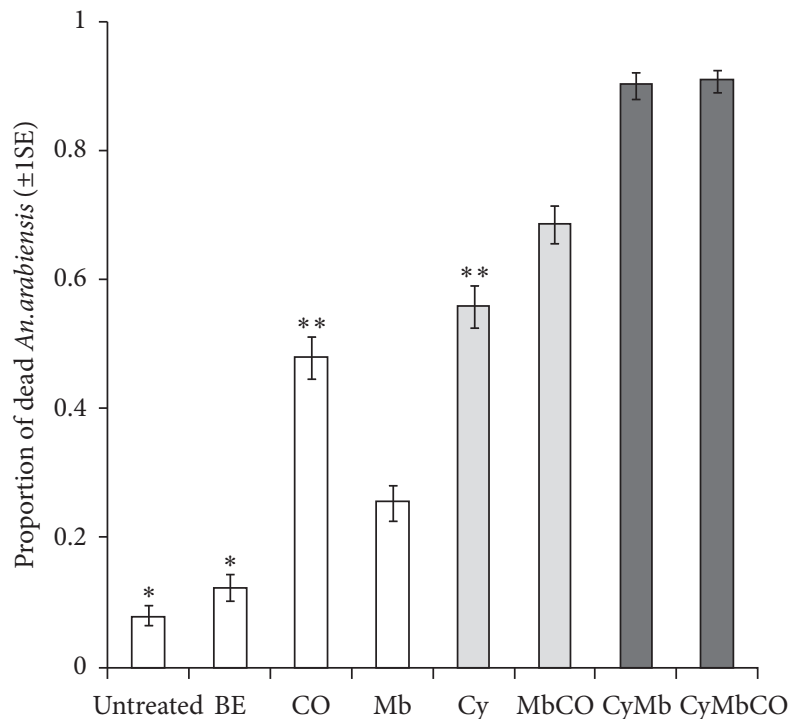

(a)

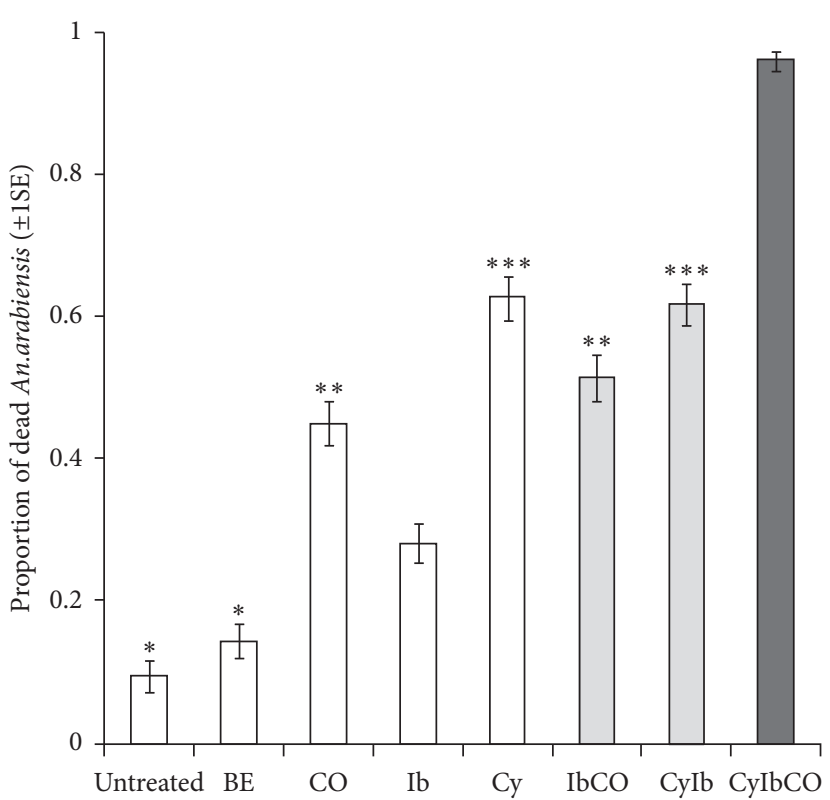

(b)

Figure 4: Estimated proportion ( \pm 1 s.e.) of An. arabiensis mosquitoes that were killed after exposure to untreated or bendiocarb-treated improved passive host seeking device baited with attractants within the semifield system: (a) Mbita blend (Mb) and cyclopentanone (Cy), (b) Ifakara blend (Ib) and cyclopentanone (Cy). The statistical significant differences between treatments are indicated as follows: the black boxes indicate that the two treatments are similar but statistically significantly different from all other treatments; the grey boxes indicate that the two are similar but statistically significantly different from all others; the different numbers of asterisks indicate statistical significant differences between treatments; the open boxes without asterisks indicate statistical significant difference from all other treatments. The treatments are abbreviated as follows: untreated: attractants without bendiocarb-treated netting, $\mathrm{BE}$ : bendiocarb-treated netting without attractants, $\mathrm{CO}$ : carbon dioxide $\left(\mathrm{CO}_{2}\right), \mathrm{Mb}$ : $\mathrm{Mbita}$ blend, $\mathrm{Cy}$ : cyclopentanone granules, $\mathrm{MbCO}$ : $\mathrm{Mbita}$ blend $\mathrm{combined} \mathrm{with} \mathrm{CO}_{2}$, $\mathrm{CyMb}$ : Mbita blend combined with cyclopentanone granules, $\mathrm{CyMbCO}$ : Mbita blend combined with cyclopentanone granules and $\mathrm{CO}_{2}$, IbCO: Ifakara blend combined with $\mathrm{CO}_{2}$, CyIb: Ifakara blend combined with cyclopentanone granules, CyIbCO: Ifakara blend combined with cyclopentanone granules and $\mathrm{CO}_{2}$. Error bars represents plus/minus 1 standard error.

carbon dioxide (CO) attracted and killed more mosquitoes than those of POHD baited with Ifakara blend (Ib). However, the two blends (Mbita and Ifakara blend), when acting alone without augmentation, attracted similar proportions of An. arabiensis to improved POHD $\left(\chi_{1}^{2}=2.56, P<0.001\right.$, Figures 4(a) and 4(b), Table 1).

The attractiveness of improved POHD baited with Mbita blend to $A n$. arabiensis varied significantly between treatments $\left(\chi_{7}^{2}=44.629, P<0.001\right.$, Figure 4(a), Tables 1 and 2$)$. The improved POHD baited with attractants alone (i.e., without bendiocarb) or bendiocarb-treated nettings without attractants acted as controls which killed similar proportion of An. arabiensis ( $z=1.68, P=0.69$, Figure 4(a), Table 1). The bendiocarb-treated POHD without attractants killed significantly fewer mosquitoes than bendiocarb-treated POHD baited with CO $(z=8.5, P<0.001), \mathrm{Mb}(z=3.69$, $P<0.001)$, Cy $(z=9.47, \quad P<0.001), \quad \mathrm{MbCO} \quad(z=11.64$, $P<0.001)$, CyMb $(z=14.34, P<0.001)$, and CyMbCO $(z=14.98, P<0.001)$ (Figure 4(a), Table 1). Similarly, the POHD baited with all three attractants but without bendiocarb-treated nettings attracted and killed fewer mosquitoes than the POHD baited with $\mathrm{CO}(z=-9.13, P<0.001), \mathrm{Mb}$ $(z=-5.15, P<0.001)$, Cy $(z=-10.29, P<0.001)$, MbCO $(z=-12.23, P<0.001)$, CyMb $(z=-14.81, P<0.001)$, and CyMbCO $(z=-15.38, P<0.001)$ (Figure 4(a), Table 1).
When $\mathrm{CO}_{2}$ was applied alone in bendiocarb-treated POHD, it attracted and killed greater proportion of mosquitoes than POHD baited with $\mathrm{Mb}$ alone $(z=5.13, P<0.0010)$, but it killed fewer mosquitoes than POHD baited with MbCO ( $z=4.61, P<0.001$ ) (Figure 4(a), Table 1). Furthermore, the $\mathrm{CO}_{2}$ enhanced attractiveness of POHD baited with Mbita blend to mosquitoes; the POHD baited with $\mathrm{MbCO}$ attracted and killed greater proportions of mosquitoes than POHD baited with $\mathrm{Mb}$ alone $(z=9.32, P<0.001)$ (Figure $4(\mathrm{a})$, Tables 1 and 2). In comparison with cyclopentanone, the bendiocarb-treated POHD baited with $\mathrm{CO}_{2}$ alone attracted and killed mosquitoes the same as POHD baited with $\mathrm{Cy}$ alone $(z=1.73, P=0.65)$, but it killed fewer mosquitoes than POHD baited with CyMb $(z=9.07, P<0.001)$ and CyMbCO $(z=9.69, P<0.001)$ (Figure 4(a), Tables 1 and 2$)$. In fact, cyclopentanone enhanced attractiveness of POHD to mosquitoes. The bendiocarb-treated POHD baited with Cy alone attracted and killed similar proportions of mosquitoes to POHD baited with $\mathrm{MbCO}(z=2.89, P=0.07$, Figure 4(a), Tables 1 and 2), but it killed greater proportion of mosquitoes than $\mathrm{POHD}$ baited with $\mathrm{Mb}$ alone $(z=6.71$, $P<0.001$, Figure 4(a), Tables 1 and 2). Furthermore, the bendiocarb-treated POHD baited with Mbita blend killed more mosquitoes when combined with cyclopentanone. The bendiocarb-treated POHD baited with $\mathrm{CyMb}$ attracted and 
TABLE 1: Summary of numbers of An. arabiensis mosquitoes exposed and their responses to the improved POHD baited with attractants alone or their different treatment combinations.

\begin{tabular}{|c|c|c|c|c|}
\hline Types of blend & $\begin{array}{c}\text { Combination of } \\
\text { treatments }\end{array}$ & $\begin{array}{c}\text { Total number of exposed } \\
\text { mosquitoes }\end{array}$ & $\begin{array}{c}\text { Total number of dead } \\
\text { mosquitoes }\end{array}$ & $\begin{array}{c}\text { Mean number of dead } \\
\text { mosquitoes }\end{array}$ \\
\hline \multirow{8}{*}{$\begin{array}{l}\text { Mbita blend } \\
(\mathrm{Mb})\end{array}$} & CyMbCO & 274 & 249 & 83.00 \\
\hline & $\mathrm{CyMb}$ & 235 & 212 & 70.67 \\
\hline & $\mathrm{MbCO}$ & 251 & 172 & 57.33 \\
\hline & Су & 240 & 134 & 44.67 \\
\hline & $\mathrm{CO}$ & 246 & 118 & 39.33 \\
\hline & $\mathrm{Mb}$ & 251 & 64 & 21.33 \\
\hline & Untreated & 267 & 21 & 7 \\
\hline & $\mathrm{BE}$ & 251 & 31 & 10.3 \\
\hline \multirow{8}{*}{$\begin{array}{l}\text { Ifakara blend } \\
\text { (Ib) }\end{array}$} & CyIbCO & 255 & 245 & 81.67 \\
\hline & CyIb & 251 & 155 & 51.67 \\
\hline & $\mathrm{IbCO}$ & 237 & 122 & 40.67 \\
\hline & Cy & 236 & 155 & 51.67 \\
\hline & $\mathrm{CO}$ & 260 & 126 & 42.00 \\
\hline & $\mathrm{Ib}$ & 242 & 68 & 22.67 \\
\hline & Untreated & 255 & 16 & 5.33 \\
\hline & $\mathrm{BE}$ & 216 & 31 & 10.33 \\
\hline
\end{tabular}

The columns of the table indicate the combination of treatments, total numbers of mosquitoes exposed to baited POHD, and total numbers and average numbers of dead An. arabiensis after exposure to the baited POHD. The treatments are abbreviated as follows: untreated: attractants without bendiocarbtreated netting, $\mathrm{BE}$ : bendiocarb-treated netting without attractants, $\mathrm{CO}$ : carbon dioxide $\left(\mathrm{CO}_{2}\right), \mathrm{Mb}$ : $\mathrm{Mbita}$ blend, $\mathrm{Cy}$ : cyclopentanone granules, $\mathrm{MbCO}$ : $\mathrm{Mbita}$ blend combined with $\mathrm{CO}_{2}, \mathrm{CyMb}$ : Mbita blend combined with cyclopentanone granules, $\mathrm{CyMbCO}$ : Mbita blend combined with cyclopentanone granules and $\mathrm{CO}_{2}$, IbCO: Ifakara blend combined with $\mathrm{CO}_{2}$, CyIb: Ifakara blend combined with cyclopentanone granules, CyIbCO: Ifakara blend combined with cyclopentanone granules and $\mathrm{CO}_{2}$.

TABLE 2: Potentiating/enhancing effects of cyclopentanone and carbon dioxide on attractiveness of synthetic blends baited POHD against An. arabiensis.

\begin{tabular}{|c|c|c|c|c|c|}
\hline Blend types & $\begin{array}{c}\text { Combination of treatments } \\
\text { of POHD }\end{array}$ & $\begin{array}{c}\text { Average number of dead } \\
\text { mosquitoes }\end{array}$ & $\begin{array}{c}\text { Individual treatments } \\
\text { of POHD }\end{array}$ & $\begin{array}{c}\text { Average number of dead } \\
\text { mosquitoes }\end{array}$ & $P$ values \\
\hline \multirow{4}{*}{$\begin{array}{l}\text { Mbita blend } \\
(\mathrm{Mb})\end{array}$} & $\mathrm{CyMb}$ & 70.67 & $\mathrm{Mb}$ & 21.33 & $P<0.001$ \\
\hline & & & Cy & 44.67 & $P<0.001$ \\
\hline & $\mathrm{MbCO}$ & 57.33 & $\mathrm{Mb}$ & 21.33 & $P<0.001$ \\
\hline & & & $\mathrm{CO}$ & 39.33 & $P<0.001$ \\
\hline \multirow{4}{*}{$\begin{array}{l}\text { Ifakara blend } \\
\text { (Ib) }\end{array}$} & CyIb & 51.67 & $\mathrm{Ib}$ & 22.67 & $P<0.001$ \\
\hline & & & Cy & 49.33 & $P=1$ \\
\hline & $\mathrm{IbCO}$ & 40.67 & $\mathrm{Ib}$ & 22.67 & $P<0.001$ \\
\hline & & & $\mathrm{CO}$ & 39.00 & $P=0.84$ \\
\hline
\end{tabular}

The potentiating effect is indicated by the average number of dead mosquitoes in a column of combined effects of synthetic blend and either cyclopentanone or carbon dioxide that is greater than the average number of dead mosquitoes in column of individual effects of synthetic blend. The treatments are abbreviated as follows: $\mathrm{CyMb}$ : Mbita blend combined with cyclopentanone, $\mathrm{Cy}$ : cyclopentanone alone, $\mathrm{CO}_{2}$ : carbon dioxide alone, $\mathrm{Mb}$ : $\mathrm{Mbita}$ blend alone, $\mathrm{Ib}$ : Ifakara blend alone, $\mathrm{MbCO}$ : Mbita blend combined with $\mathrm{CO}_{2}$, IbCO: Ifakara blend combined with $\mathrm{CO}_{2}$, $\mathrm{CyIb}$ : Ifakara blend combined with cyclopentanone.

killed similar proportions of mosquitoes to POHD baited with CyMbCO $(z=0.25, P=1$, Figure 4(a), Table 1), but it killed greater proportion of mosquitoes than POHD baited with $\mathrm{Mb}$ alone $(z=-12.52, P<0.001$, Figure $4(\mathrm{a})$, Tables 1 and 2$)$ and $\mathrm{MbCO}(z=-5.59, P<0.001$, Figure 4(a), Tables 1 and 2). Similarly, the bendiocarb-treated POHD baited with CyMbCO killed more mosquitoes than POHD baited with Mb alone $(z=-13.22, P<0.001$, Figure $4(a)$, Table 1$)$ and $\operatorname{MbCO}(z=-6.08, P<0.001$, Figure 4(a), Table 1$)$.

Similarly, the attractiveness of POHD baited with Ifakara blend to $A n$. arabiensis varied significantly between treatments $\left(\chi_{7}^{2}=48.79, P<0.001\right.$, Figure $\left.4(\mathrm{~b})\right)$. The bendiocarbuntreated POHD baited with attractants and the bendiocarb-treated POHD without attractants were the controls for the combination of treatments which attracted and killed similar proportion of mosquitoes $(z=1.34, \quad P=0.87$, Figure 4(b), Table 1). The bendiocarb-treated POHD without attractants (BE) killed relatively lower proportion of $A n$. arabiensis than bendiocarb-treated POHD baited with different treatment combinations including CO $(z=6.89$, $P<0.001)$, Cy $(z=9.79, P<0.001$, Figure $4(\mathrm{~b}))$, $\mathrm{Ib}(z=3.51$, $P<0.001$, Figure 4(b)), IbCO $(z=7.09, \quad P<0.001$, Figure 4(b)), CyIb $(z=9.72, P<0.001$, Figure $4(\mathrm{~b}))$, and CyIbCO $(z=13.25, P<0.001$, Figure $4(\mathrm{~b}))$. Likewise, the bendiocarb-untreated POHD baited with all three attractants killed fewer proportions of mosquitoes than bendiocarb-treated POHD baited with $\mathrm{CO}(z=-6.93, P<0.001)$, Cy $(z=-9.30, P<0.001)$, Ib $(z=-4.27, P<0.001)$, IbCO $(z=-7.71, \quad P<0.001)$, CyIb $(z=-9.21, \quad P<0.001)$, and CyIbCO $(z=-13.01, P<0.001)$. The yeast fermentation- 
produced $\mathrm{CO}_{2}$ applied to bendiocarb-treated POHD enhanced attractiveness of this device to An. arabiensis; consequently, this POHD killed similar proportion of these mosquitoes as bendiocarb-treated POHD baited with $\mathrm{IbCO}$ $(z=1.41, P=0.84)$, but it killed more mosquitoes than POHD baited with $\mathrm{Ib}$ alone $(z=-3.91, P=0.002$, Figure 4(b), Tables 1 and 2). In addition, the bendiocarb-treated POHD baited with $\mathrm{IbCO}$ attracted and killed more mosquitoes than POHD baited with Ib alone $(z=5.15, P<0.001$, Figure 4(b), Tables 1 and 2). In comparison with cyclopentanone, the POHD baited with $\mathrm{CO}_{2}$ alone attracted and killed significantly lower proportion of mosquitoes than POHD baited with different treatment combinations of cyclopentanone such as Cy alone $(z=3.96, P=0.001$, Figure $4(\mathrm{~b})$, Tables 1 and 2), CyIb $(z=3.79, P=0.003$, Figure $4(\mathrm{~b})$, Tables 1 and $2)$, and CyIbCO $(z=-9.83, P<0.001$, Figure 4(b), Table 1$)$. Indeed, cyclopentanone enhanced attractiveness of POHD to $A n$. arabiensis when applied alone or in combination with Ifakara blend. The bendiocarb-treated POHD baited with Cy alone lured and killed similar proportion of these mosquitoes to POHD baited with CyIb $(z=-0.23, P=1)$ and IbCO $(z=-2.52, P=0.17)$, but it killed more mosquitoes than POHD baited with $\mathrm{Ib}$ alone $(z=-7.47, P<0.001)$. The bendiocarb-treated POHD baited with CyIb attracted and killed similar proportion of mosquitoes to POHD baited with $\operatorname{IbCO}(z=-2.34, P=0.26$, Figure $4(b))$, but its attractiveness to mosquitoes was greater than that of POHD baited with Ib alone $(z=-7.37, \quad P<0.001$, Figure 4(b), Tables 1 and 2). Furthermore, bendiocarbtreated POHD baited with all three attractants (CyIbCO) strongly attracted and killed more mosquitoes than POHD baited with $\mathrm{Ib}$ alone $(z=-11.74, P<0.001$, Figure $4(\mathrm{~b})$, Table 1$)$, IbCO $(z=-9.04, P<0.001$, Figure $4(\mathrm{~b})$, Table 1$)$, and CyIb $(z=7.81, P<0.001)$.

4.2. Persistence of Granular Formulation of Cyclopentanone. The attractiveness of POHD against Anopheles arabiensis was influenced by the persistence of cyclopentanone granules $\left(\chi_{4}^{2}=34.48, P<0.001\right.$, Figure 5). Bendiocarb-treated POHD baited with fresh granules of cyclopentanone (FreshCy) or their combination with granules of Mbita blend (FreshCyMb) attracted and killed similar proportions of mosquitoes $(z=1.26, P=0.79$, Figure 5). However, bendiocarb-treated POHD baited with 2-month-old granular cyclopentanone (2moCy), or 2-month-old granular cyclopentanone combined with Mbita blend (2moCyMb) attracted and killed significantly lower proportion of mosquitoes than that of POHD baited with fresh granular cyclopentanone (FreshCy) and their combination with Mbita blend $(P<0.001$, in all cases, Figure 5). The POHDs baited with $2 \mathrm{moCy}, 2 \mathrm{moCyMb}$, FreshCy, and FreshCyMb attracted and killed significantly greater proportion of mosquitoes than $\mathrm{POHD}$ baited with Mbita blend alone $(P<0.001$, in all cases, Figure 5$)$. However, POHD baited with $2 \mathrm{moCy}$ attracted and killed significantly fewer mosquitoes than POHD baited with combination of $2 \mathrm{moCy}$ and Mbita blend ( $z=8.51, P<0.001$, Figure 5). Moreover, POHD without bendiocarb attracted and killed significantly fewer mosquitoes than all other POHDs baited

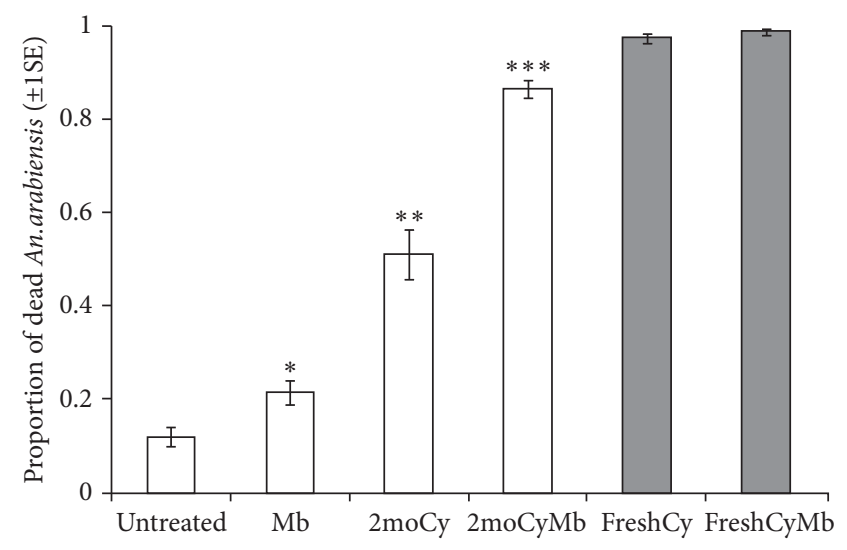

FIgURE 5: Estimated proportion ( \pm 1 s.e.) of An. arabiensis mosquitoes that were attracted and killed after exposure to an improved passive host seeking device that was untreated or treated with bendiocarb (BE) and baited with fresh or 2-month-old granules of cyclopentanone $(\mathrm{Cy})$ or their combinations with fresh granules of Mbita blend $(\mathrm{Mb})$ in a rectangular bioassay box within the semifield system. The statistical significant differences between treatments are indicated as follows: the black boxes indicate statistical significant differences from all other treatments; the different numbers of asterisks indicate statistical significant differences between treatments; no asterisk or color indicates statistical significant differences from all other treatments. The treatments are abbreviated as follows: untreated: attractants without bendiocarb-treated netting, Mb: Mbita blend, 2moCy: 2-month-old granules of cyclopentanone, 2moCyMb: 2-month-old granules of cyclopentanone combined with Mbita blend, FreshCy: fresh granules of cyclopentanone, and fresh $\mathrm{CyMb}$ : fresh granules of cyclopentanone combined with Mbita blend. Error bars represents \pm 1 standard error.

with cyclopentanone alone or cyclopentanone combined with Mbita blend regardless of the age of the granules $(P<0.001$, in all cases, Figure 5).

\subsection{Efficacy of Different Formulations of Cyclopentanone.} The efficacy of POHD baited with cyclopentanone varied significantly between treatments $\left(\chi_{2}^{2}=16.16\right.$, $P<0.001$, Figure 6). The POHD without bendiocarb attracted and killed significantly lower proportion of mosquitoes than bendiocarb-treated POHD baited with granular cyclopentanone $(z=10.59, P<0.001$, Figure 6$)$ and cyclopentanone impregnated nylon strips $(z=14.60, P<0001$, Figure 6). However, POHD baited with cyclopentanone impregnated nylon strips attracted and killed similar proportion of mosquitoes to POHD baited with cyclopentanone granules $(z=-2.27, P=0.05$, Figure 6$)$.

\section{Discussion}

This study revealed the potential of granular formulation of cyclopentanone as an alternative to artificial $\mathrm{CO}_{2}$ applied in odor-baited traps against An. arabiensis that maintains residual transmission of malaria in most of African countries. The improved POHD baited with granular cyclopentanone 


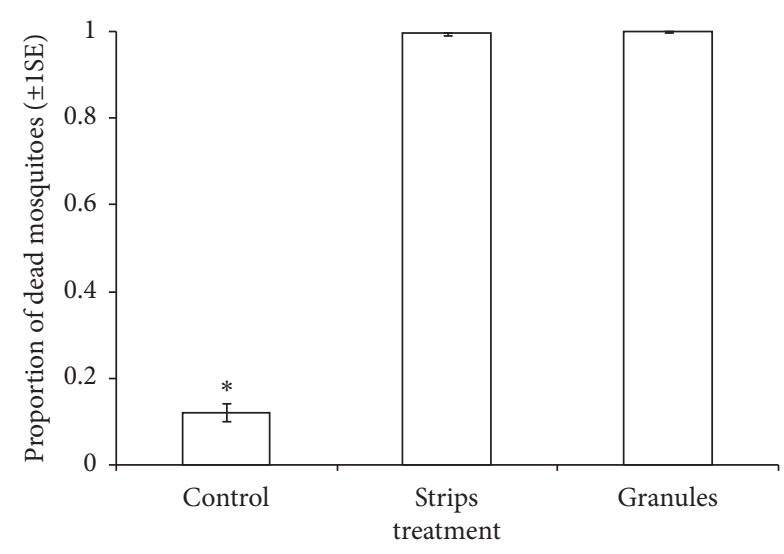

FIGURE 6: Estimated proportion ( \pm 1 s.e.) of An. arabiensis mosquitoes that were attracted and killed after exposure to an improved passive host seeking device that was untreated or treated with bendiocarb (BE) and baited with impregnated nylon strips or granular formulations of cyclopentanone (Cy) in combination with Mbita blend (Mb) in a rectangular bioassay box within the semifield system. The treatments were abbreviated as follows: control: attractants without benthiocarb-treated nettings, strips: cyclopentanone impregnated nylon strips, granules: granular cyclopentanone. The statistical significant differences between treatments are indicated as follows: the asterisks indicate statistical significant differences from all other treatments with open boxes without asterisks. Error bars represent \pm 1 standard error.

was attractive as much as, or more than, the POHD baited with fermented $\mathrm{CO}_{2}$ to An. arabiensis. Plumes of both the granular cyclopentanone and $\mathrm{CO}_{2}$ act in the same way on mosquitoes $\mathrm{CO}_{2}$ receptors (cpA). This finding compares with the results of recent semifield and field experiments that tested liquid formulations of 2-butanone combined with nylon strips of Mbita blend [60] and previous semifield experiment that used liquid formulation of $20 \%$ cyclopentanone [17]. However, these results were both different from that of the field trial conducted by Philippe-Janon et al. [58]. Such contrast was attributed to the quick loss of attractiveness by liquid formulation cyclopentanone under field settings consequent to strong wind as well as fluctuations on temperature and relative humidity. Therefore, the slow release formulation (granules) of cyclopentanone offers an exciting option for use in odor-baited mosquito surveillance and/or control devices. Sachet of granular cyclopentanone is less bulky and easy to apply and distribute in large scale surveillance compared to other sources of $\mathrm{CO}_{2}$ such as pressurized cylinder of $\mathrm{CO}_{2}$ and gallons for yeast fermentation-produced $\mathrm{CO}_{2}$, and it lasts relatively longer than liquid formulations $[17,58,60]$. Thus, it can be deployed in resource poor areas like rural Tanzania. Although production of $\mathrm{CO}_{2}$ from a mixture of yeast and molasses was in certain circumstances as effective as, or less effective than, cyclopentanone, it has a drawback in that the mixture of materials in portable containers can release $\mathrm{CO}_{2}$ for approximately 8-12 hours and resources are highly needed for domestic consumption and logistically difficult to change and distribute on daily basis for large scale surveillance and control of mosquitoes.
Also, this study indicated that granular cyclopentanone had stronger potentiating/enhancing effect on synthetic blends than that of the yeast fermentation-produced $\mathrm{CO}_{2}$. Such effect of cyclopentanone on synthetic blends varied between blend types applied on the POHD. Nevertheless, the granular formulation of cyclopentanone enhanced/potentiated attractiveness of POHD baited with Mbita blend to An . arabiensis by $70 \%$, but it enhanced the attractiveness of POHD baited with Ifakara blend by $56 \%$. Previous semifield and field experiments indicated that Mbita blend is relatively more attractive to mosquitoes than Ifakara blend when augmented with $\mathrm{CO}_{2}$ [63]. The current study also found that the combinations of either blend with cyclopentanone or $\mathrm{CO}_{2}$ in POHD attracted far greater proportion of mosquitoes relative to the individual blends, $\mathrm{Cy}$ alone, or $\mathrm{CO}_{2}$ alone. This observation that $\mathrm{CO}_{2}$ enhances attractiveness of odor blends is also emphasized in several studies conducted elsewhere $[11,16,30,37,38,43]$. The results of this study also confirms the recent findings that traps baited with Mbita blend and augmented with $\mathrm{CO}_{2}$ mimic compounds such as 2-butanone attracted similar number of mosquitoes as those traps baited with odor blends combined with $\mathrm{CO}_{2}$ gas [60]. Since plumes of cyclopentanone and $\mathrm{CO}_{2}$ act in the same way on mosquito's $\mathrm{CO}_{2}$ receptors [17], they may be used to augment synthetic blends in POHD and other devices of the sort.

Moreover, the residual activity of 2-month-old granular cyclopentanone was reduced by $47 \%$ relative to the fresh formulation when applied in POHD. Nevertheless, when such formulation was complemented with Mbita blend, the efficacy was elevated to $76 \%$. Such stable residual activity of cyclopentanone could have been contributed by their storage under refrigeration temperature between experiments and slow release granular formulation. This slow release formulation may have enabled the older cyclopentanone to retain its enhancement/potentiation effects on synthetic blends in the POHD that attracted and killed $>80 \%$ of the exposed mosquitoes. Similarly, previous studies showed that the application of BG lures as granules increased their residual activity for up to 5 months [34, 72]. These findings therefore indicate that attractiveness of cyclopentanone granules lasts for relatively longer time after application than other $\mathrm{CO}_{2}$ sources and thus will need to be replaced less frequently when applied in odor-baited traps for large scale vector surveillance and control.

On the other hand, fresh granules and nylon strips of cyclopentanone were equally effective in enhancing attractiveness of POHD baited with Mbita blend against $A n$. arabiensis. The possible explanation could be that these experiments were conducted within a small sized chamber $(1.87 \times 2.12 \times 1.15 \mathrm{~m})$ where cyclopentanone with high volatility, when used alone or combined with Mbita blend, yielded equal concentration of odor plumes in a short range/ distance to mosquitoes regardless of the formulations. Therefore, mosquitoes equally detected the plumes from different treatments. Variation between the two formulations could have been observed if they were compared under natural field conditions. Previous field work demonstrated that traps baited with nylon strip impregnated with Mbita blend combined with $\mathrm{CO}_{2}$ attracted as much Aedes and 
Culex mosquitoes as the traps baited with combination of long-lasting granular formulation of $\mathrm{BG}$ lures and $\mathrm{CO}_{2}$ [37]. Contrastingly, the recent study demonstrated that fresh liquid formulation of 2-butanone combined with synthetic odor blend attracted more Anopheles mosquitoes to the traps than traps baited with odor blend alone in the field, but not under the semifield conditions [60].

Although impregnated nylon strips of synthetic blends have been shown to remain attractive to mosquitoes for several weeks to months $[34,35,43,63,73]$, they are not suitable for mass production and use in large scale mosquito surveillance and control programs [54]. Overall, the granular formulation of cyclopentanone may be portable, durable, lightweight, and easy to produce and use in odor-baited devices for large scale surveillance and control of mosquitoes. However, further investigations are required to assess long-lasting enhancing effects of granular formulations of cyclopentanone on synthetic blends in natural environments.

In conclusion, the present study demonstrates that cyclopentanone has the potential to substitute artificial source of $\mathrm{CO}_{2}$ in odor-baited devices for surveillance and control of An. arabiensis, thus warranting evaluation of such alternative under realistic field conditions.

\section{Data Availability}

The data used to support the findings of this study are available from the corresponding author upon request.

\section{Conflicts of Interest}

The authors declare that they have no conflicts of interest.

\section{Authors' Contributions}

STK and INL designed the experiments and supervised their execution. STK, INL, and LLM performed the experiments. STK and INL analyzed the data and drafted the manuscript. INL, LLM, and BAN critically reviewed the manuscript. All authors read and approved the final version of the manuscript.

\section{Acknowledgments}

Many thanks are due to all partners of the European Union funded project for the fruitful discussions. Also, thanks are due to our consortium partner, Biogents AG, Regensburg, Germany, for providing granular and impregnated-nylon strips formulation of cyclopentanone and synthetic blends (Mbita and Ifakara blend). We thank Mr. Ignasi Mlichi for assisting in designing and producing different experimental prototypes of the POHD. Our deep appreciation is extended to all technical staff for their support: Ally Daraja, Kassian Mbina, Cletus Mtimalias, Godfrey Matanila, Gudluck Mpumu, and Samwel Makayula. This work was supported by European Union Seventh Framework (Grant 306105, FP7Health, 2012-INNOVATION-1).

\section{References}

[1] WHO, 2015, Chikungunya, World Health Organization, Geneva, Switzerland, 2015.

[2] WHO, 2015 Global Technical Strategy for Malaria 2016-2030, World Health Organization, Geneva, Switzerland, 2015.

[3] WHO, 2008, Rift Valley Fever Outbreaks Forecasting Models Rome, Italy, World Health Organization, Geneva, Switzerland, 2008.

[4] World Health Organization, "World malaria report 2018," World Health Organization, Geneva, Switzerland, 2018.

[5] World Health Organization, "World malaria report 2014," World Health Organization, Geneva, Switzerland, 2014.

[6] World Health Organization, "World malaria report 2019," World Health Organization, Geneva, Switzerland, 2019.

[7] WHO, 2015, Lymphatic Filariasis, World Health Organization, Geneva, Switzerland, 2015.

[8] World Health Organization, "World malaria report 2013," World Health Organization, Geneva, Switzerland, 2013.

[9] W. Takken, "The role of olfaction in host-seeking of mosquitoes: a review," International Journal of Tropical Insect Science, vol. 12, no. 1-3, pp. 287-295, 1991.

[10] M. Ditzen, M. Pellegrino, and L. B. Vosshall, "Insect odorant receptors are molecular targets of the insect repellent DEET," Science, vol. 319, no. 5871, pp. 1838-1842, 2008.

[11] C. J. McMeniman, R. A. Corfas, B. J. Matthews, S. A. Ritchie, and L. B. Vosshall, "Multimodal integration of carbon dioxide and other sensory cues drives mosquito attraction to humans," Cell, vol. 156, no. 5, pp. 1060-1071, 2014.

[12] B. A. Omondi, S. Majeed, and R. Ignell, "Functional development of carbon dioxide detection in the maxillary palp of Anopheles gambiae," Journal of Experimental Biology, vol. 218, no. 15, pp. 2482-2488, 2015.

[13] J. Spitzen, R. C. Smallegange, and W. Takken, "Effect of human odours and positioning of $\mathrm{CO}_{2}$ release point on trap catches of the malaria mosquito Anopheles gambiae sensu stricto in an olfactometer," Physiological Entomology, vol. 33, no. 2, pp. 116-122, 2008.

[14] W. Takken and B. G. J. Knols, "Odor-mediated behavior of Afrotropical malaria mosquitoes," Annual Review of Entomology, vol. 44, no. 1, pp. 131-157, 1999.

[15] A. F. Carey, G. Wang, C.-Y. Su, L. J. Zwiebel, and J. R. Carlson, "Odorant reception in the malaria mosquito Anopheles gambiae," Nature, vol. 464, no. 7285, pp. 66-71, 2010.

[16] Y. T. Qiu and J. J. van Loon, "Olfactory physiology of bloodfeeding vector mosquitoes," in Olfaction in Vector-Host Interactions, pp. 39-61, Wageningen Academic Publishers, Wageningen, Netherlands, 2010.

[17] G. M. Tauxe, D. MacWilliam, S. M. Boyle, T. Guda, and A. Ray, "Targeting a dual detector of skin and $\mathrm{CO}_{2}$ to modify mosquito host seeking," Cell, vol. 155, no. 6, pp. 1365-1379, 2013.

[18] R.-D. Xue, M. A. Doyle, and D. L. Kline, "Field evaluation of $\mathrm{CDC}$ and mosquito magnet $\mathrm{X}$ traps baited with dry ice, $\mathrm{CO}_{2}$ sachet, and octenol against mosquitoes," Journal of the American Mosquito Control Association, vol. 24, no. 2, pp. 249-252, 2008.

[19] T. Dekker, M. Geier, and R. Carde, "Carbon dioxide instantly sensitizes female yellow fever mosquitoes to human skin odours," Journal of Experimental Biology, vol. 208, no. 15, pp. 2963-2972, 2005.

[20] T. Dekker, W. Takken, and R. T. Carde, "Structure of host odour plumes influences catch of Anopheles gambiae ss and 
Aedes aegypti in a dual choice olfactometer," Physiological Entomology, vol. 26, no. 2, pp. 124-134, 2001.

[21] M. T. Gillies, "The role of carbon dioxide in host-finding by mosquitoes (Diptera: Culicidae): a review," Bulletin of Entomological Research, vol. 70, no. 4, pp. 525-532, 1980.

[22] W. R. Mukabana, W. Takken, P. Seda, G. F. Killeen, W. A. Hawley, and B. G. J. Knols, "Extent of digestion affects the success of amplifying human DNA from blood meals of Anopheles gambiae (Diptera: Culicidae)," Bulletin of Entomological Research, vol. 92, no. 3, pp. 233-239, 2002.

[23] W. R. Mukabana, W. Takken, G. F. Killeen et al., "Academic ecologists at African universities can empower communities to control malaria," Malaria Journal, vol. 3, no. 1, pp. 1-8, 2004.

[24] J. Spitzen, C. W. Spoor, F. Grieco et al., "A 3D analysis of flight behavior of Anopheles gambiae sensu stricto malaria mosquitoes in response to human odor and heat," PLoS One, vol. 8, no. 5, Article ID e62995, 2013.

[25] M. T. Gillies and B. DeMeillon, The Anophelinae of Africa South of the Sahara (Ethiopian Zoogeographical Region), South African Institute for Medical Research, Johannesburg, South Africa, 1968.

[26] M. T. Gillies and T. J. Wilkes, "The range of attraction of animal baits and carbon dioxide for mosquitoes. Studies in a freshwater area of West Africa," Bulletin of Entomological Research, vol. 61, no. 3, pp. 389-404, 1972.

[27] C. Costantini, G. Gibson, N. F. Sagnon, A. D. Torre, J. Brady, and M. Coluzzi, "Mosquito responses to carbon dioxide in B west African Sudan savanna village," Medical and Veterinary Entomology, vol. 10, no. 3, pp. 220-227, 1996.

[28] M. Jawara, R. C. Smallegange, D. Jeffries et al., "Optimizing odor-baited trap methods for collecting mosquitoes during the malaria season in the Gambia," PLoS One, vol. 4, no. 12, Article ID e8167, 2009.

[29] L. E. G. Mboera, B. G. J. Knols, W. Takken, and A. della Torre, "The response of Anopheles gambiae s.l. and A. funestus (Diptera: Culicidae) to tents baited with human odour or carbon dioxide in Tanzania," Bulletin of Entomological Research, vol. 87, no. 2, pp. 173-178, 1997.

[30] B. N. Nouage, W. R. Mukabana, W. Takken, and B. G. Knols, "Trapping of the malaria vector Anopheles gambiae with odour-baited MM-X traps in semi-field conditions in western Kenya," Malaria Journal, vol. 5, no. 1, p. 39, 2006.

[31] J. J. A. van Loon, R. C. Smallegange, G. Bukovinszkiné-Kiss et al., "Mosquito attraction: crucial role of carbon dioxide in formulation of a five-component blend of human-derived volatiles," Journal of Chemical Ecology, vol. 41, no. 6, pp. 567-573, 2015.

[32] R. C. Smallegange, W. H. Schmied, K. J. van Roey et al., "Sugar-fermenting yeast as an organic source of carbon dioxide to attract the malaria mosquito Anopheles gambiae," Malaria Journal, vol. 9, no. 2, 2010.

[33] T. Chaiphongchapara, P. Bunyuen, and K. K. Chansukh, "Development of a more effective mosquito trapping box for vector control," The Scientific World Journal, vol. 2018, Article ID 6241703, 8 pages, 2018.

[34] N. S. Matowo, L. L. Koekemoer, S. J. Moore et al., "Combining synthetic human odours and low-cost electrocuting grids to attract and kill outdoor-biting mosquitoes: field and semifield evaluation of an improved mosquito landing box," PLoS One, vol. 11, no. 1, Article ID e0145653, 2016.

[35] N. S. Matowo, J. Moore, S. Mapua et al., "Using a new odourbaited device to explore options for luring and killing outdoor-biting malaria vectors: a report on design and field evaluation of the mosquito landing box," Parasite \& Vectors, vol. 6, pp. 1-16, 2013.

[36] F. Okumu, G. Killeen, S. Ogoma et al., "Development and field evaluation of a synthetic mosquito lure that is more attractive than humans," PLoS One, vol. 5, no. 1, Article ID e8951, 2010.

[37] M. Pombi, F. Jacobs, N. O. Verhulst, B. Caputo, A. Della Torre, and W. Takken, "Field evaluation of a novel synthetic odour blend and of the synergistic role of carbon dioxide for sampling host-seeking Aedes albopictus adults in Rome, Italy," Parasite \& Vectors, vol. 7, no. 1, pp. 1-5, 2014.

[38] Y.-T. Qiu, G. Gort, R. Torricelli, W. Takken, and J. J. A. van Loon, "Effects of blood-feeding on olfactory sensitivity of the malaria mosquito Anopheles gambiae: application of mixed linear models to account for repeated measurements," Journal of Insect Physiology, vol. 59, no. 11, pp. 1111-1118, 2013.

[39] P. Sriwichai, S. Karl, Y. Samung et al., "Evaluation of CDC light traps for mosquito surveillance in a malaria endemic area on the Thai-Myanmar border," Parasites \& Vectors, vol. 8, no. 1, pp. 1-10, 2015.

[40] B. Van de Straat, A. Hiscox, W. Takken, and T. R. Burkot, "Evaluating synthetic odours and trap designs for monitoring Anopheles farauti in Queensland, Australia," Malaria Journal, vol. 18, no. 1, p. 299, 2019.

[41] D. L. Kline, "Traps and trapping techniques for adult mosquito control," Journal of the American Mosquito Control Association, vol. 22, no. 3, pp. 490-496, 2006.

[42] L. E. G. Mboera, B. G. J. Knols, M. A. H. Braks, and W. Takken, "Comparison of carbon dioxide-baited trapping systems for sampling outdoor mosquito populations in Tanzania," Medical and Veterinary Entomology, vol. 14, no. 3, pp. 257-263, 2000.

[43] F. O. Okumu, E. P. Madumla, A. N. John, D. W. Lwetoijera, and R. D. Sumaye, "Attracting, trapping and killing diseasetransmitting mosquitoes using odor-baited stations -the ifakara odor-baited stations," Parasites \& Vectors, vol. 3, no. 1, p. 12, 2010.

[44] K. Oli, J. Jeffery, and I. Vythilingam, "Research note: a comparative study of adult mosquito trapping using dry ice and yeast generated carbon dioxide," Tropical Biomedicine, vol. 22, no. 2, pp. 249-251, 2005.

[45] D. L. Kline, "Evaluation of various models of propanepowered mosquito traps," Journal of Vector Ecology: Journal of the Society for Vector Ecology, vol. 27, no. 1, pp. 1-7, 2002.

[46] W. H. Meeraus, J. S. Armistead, and J. R. Arias, "Field comparison of novel and gold standard traps for collecting Aedes albopictus in northern Virginia," Journal of the American Mosquito Control Association, vol. 24, no. 2, pp. 244-248, 2008.

[47] D. L. Kline, "Comparison of two American biophysics mosquito traps: the professional and a new counterflow geometry trap," Journal of the American Mosquito Control News, vol. 15, pp. 276-282, 1999.

[48] D. L. Kline, S. A. Allan, U. R. Bernier, and K. H. Posey, "Olfactometer and large cage evaluation of a solid phase technology for the controlled production of $\mathrm{CO}_{2}$," Journal of the American Mosquito Control Association, vol. 22, no. 3, pp. 378-381, 2006.

[49] R. W. Mukabana, W. Takken, R. Coe, G. F. Killeen, and B. G. J. Knols, "Allomonal effect of breath contributes to differential attractiveness of humans to the African malaria vector Anopheles gambiae," Malaria Journal, vol. 3, no. 1, 2003. 
[50] C. K. Mweresa, W. R. Mukabana, P. Omusula et al., "Evaluation of textile substrates for dispensing synthetic attractants for malaria mosquitoes," Parasites \& Vectors, vol. 7, no. 1, p. 376, 2014.

[51] J. F. Harwood, A. G. Richardson, J. A. Wright, and P. J. Obenauer, "Field assessment of yeast-and oxalic acid-generated carbon dioxide for mosquito surveillance1," Journal of the American Mosquito Control Association, vol. 30, no. 4, pp. 275-283, 2014.

[52] D. C. T. Jerry, T. Mohammed, and A. Mohammed, "Yeastgenerated $\mathrm{CO}_{2}$ : a convenient source of carbon dioxide for mosquito trapping using the BG-sentinel traps," Asian Pacific Journal of Tropical Biomedicine, vol. 7, no. 10, pp. 896-900, 2017.

[53] M. Jawara, T. S. Awolola, M. Pinder et al., "Field testing of different chemical combinations as odour baits for trapping wild mosquitoes in the Gambia," PLoS One, vol. 6, no. 5, Article ID e19676, 2011.

[54] C. K. Mweresa, P. Omusula, B. Otieno, J. J. Van Loon, W. Takken, and W. R. Mukabana, "Molasses as a source of carbon dioxide for attracting the malaria mosquitoes Anopheles gambiae and Anopheles funestus," Malaria Journal, vol. 13, no. 1, p. 160, 2014.

[55] C. Webb and R. Russell, "Evaluation of granular carbon dioxide sachets for use in combination with CDC and EVS light traps for collecting mosquitoes," A report prepared for ICA, Institute of Clinical Pathology and Medical Research (ICPMR), University of Sydney, Western Sydney Area Health Services, Westmead, Australia, 2004.

[56] D. F. Hoel, J. C. Dunford, D. L. Kline et al., "A comparison of carbon dioxide sources for mosquito capture in centers for disease control and prevention light traps on the Florida gulf coast1," Journal of the American Mosquito Control Association, vol. 31, no. 3, pp. 248-257, 2015.

[57] D. Farenhorst, D. Bickers, M. Bruze et al., "A toxicological and dermatological assessment of aryl alkyl alcohol simple acid ester derivatives when used as fragrance ingredients," Food and Chemical Toxicology, vol. 50, pp. S269-S313, 2012.

[58] J. C. D. Philippe-Janon, A. F. van den Hurk, D. P. Francis, M. A. Shivas, and C. C. Jansen, "Field comparison of cyclopentanone versus carbon dioxide as an attractant for adult mosquitoes in Southeast Queensland, Australia," Journal of Medical Entomology, vol. 52, no. 3, pp. 483-490, 2015.

[59] L. E. G. Mboera, W. Takken, and E. Z. Sambu, "The response of Culex quinquefasciatus (Diptera: Culicidae) to traps baited with carbon dioxide, 1-octen-3-ol, acetone, butyric acid and human foot odour in Tanzania," Bulletin of Entomological Research, vol. 90, no. 2, pp. 155-159, 2000.

[60] M. M. Mburu, C. K. Mweresa, P. Omusula, A. Hiscox, W. Takken, and W. R. Mukabana, "2-butanone as a carbon dioxide mimic in attractant blends for the afrotropical malaria mosquitoes Anopheles gambiae and Anopheles funestus," Malaria Journal, vol. 16, no. 1, p. 351, 2017.

[61] S. L. Turner, N. Li, T. Guda, J. Githure, R. T. Cardé, and A. Ray, "Ultra-prolonged activation of $\mathrm{CO}_{2}$-sensing neurons disorients mosquitoes," Nature, vol. 474, no. 7349, pp. 87-91, 2011.

[62] I. N. Lyimo, D. T. Hydon, T. L. Russell et al., "The impact of host selection and vector control measures on the fittness of African malaria vectors," Proceedings of the Royal Society B: Biological Sciences, vol. 280, p. 1574, Article ID 20122823, 2013.
[63] W. R. Mukabana, C. K. Mweresa, B. Otieno et al., "A novel synthetic odorant blend for trapping of malaria and other African mosquito species," Journal of Chemical Ecology, vol. 38, no. 3, pp. 235-244, 2012.

[64] R. L. Aldridge, S. C. Britch, S. A. Allan et al., "Comparison of volatiles and mosquito capture efficacy for three carbohydrate sources in a yeast-fermentation $\mathrm{CO}_{2}$ generator," Journal of the American Mosquito Control Association, vol. 32, no. 4, pp. 282-291, 2016.

[65] T. I. Rosanti, S. J. Mardihusodo, and W. T. Artama, "Effectiveness of environmentally friendly mosquito trap contained sugar yeast solution," Jurnal Kesehatan Masyarakat, vol. 12, no. 2, pp. 270-276, 2017.

[66] R. Andriessen, J. Snetselaar, R. A. Suer et al., "Electrostatic coating enhances bioavailability of insecticides and breaks pyrethroid resistance in mosquitoes," Proceedings of the National Academy of Sciences, vol. 112, no. 39, pp. 1208112086, 2015.

[67] S. Sperling, "Eave tubes for malaria control in Africa: videographic observations of mosquito behaviour in Tanzania with a simple and rugged video surveillance system," 2017.

[68] D. W. Lwetoijera, C. Harris, S. Kiware et al., "Increasing role of Anopheles funestus and Anopheles arabiensis in malaria transmission in the Kilombero valley, Tanzania," Malaria Journal, vol. 13, no. 1, p. 331, 2014.

[69] N. S. Matowo, "Fine-scale spatial and temporal heterogeneities in insecticide resistance profiles of the malaria vector, Anopheles arabiensis in rural south-eastern Tanzania," Wellcome Open Research, vol. 2, p. 96, 2017.

[70] D. J. Matiya, A. B. Philbert, W. Kidima, and J. J. Matowo, "Dynamics and monitoring of insecticide resistance in malaria vectors across mainland Tanzania from 1997 to 2017: a systematic review," Malaria Journal, vol. 18, no. 1, p. 102, 2019.

[71] M. J. Crawley, "Mixed effects models," in The R Book, p. 461, 2nd edition, Wiley, Hoboken, NJ, USA, 2007.

[72] Sipes, Biogents Human Mimic Scents 2014.

[73] C. K. Mweresa, B. Otieno, P. Omusula et al., "Understanding the long-lasting attraction of malaria mosquitoes to odor baits," PLoS One, vol. 10, no. 3, pp. 1-16, 2015. 